\title{
Automated music selection of video ads
}

\author{
Oliver WIESENER \\ Stuttgart Media University, Stuttgart, Germany \\ wiesener@hdm-stuttgart.de
}

\begin{abstract}
The importance of video ads on social media platforms can be measured by views. For instance, Samsung's commercial ad for one of its new smartphones reached more than 46 million viewers at Youtube. A video ad addresses the visual as well as the auditive sense of users. Often the visual sense is busy in the sense that users focus other screens than the screen with the video ad. This is called the second screen syndrome. Therefore, the importance of the audio channel seems to grow. To get back the visual attention of users that are deflected from other visual impulses it appears reasonable to adapt the music to the target group. Additionally, it appears useful to adapt the music to content of the video. Thus, the overall success of a video ad could by increased by increasing the attention of the users. Humans typically make the decision about the music of a video ad. If there is a correlation between music, products and target groups, a digitization of the music selection process seems to be possible. Since the digitization progress in the music sector is mainly focused on music composing this article strives for making a first step towards the digitization of the music selection.
\end{abstract}

Keywords: music selection, digitization, automation, video ad, music genres.

\section{Introduction}

Video ads consist typically of a video and an audio channel whereas these channels can be seen as one unit from a consumer perspective (Bode, 2009; Hofmann, 2010). From an auditive perspective, music has in particular an effect on users, when it is combined with visual elements (Schramm, 2007). Following Schramm (2007), the target of music in online videos can be seen in getting attention. However, social media websites consist typically of plenty of visual elements. Thus, there's the danger to overexcite the visual attention of potential customers. An empirical study $(n=241)$ at the Stuttgart Media University revealed that $93 \%$ of all participants uses a second screen while watching videos. In those cases the video ad gets recognized only auditive. Thus, there is a separation between the video- and audio channel on the consumer side. Following the empirical study, the music of commercial video ads can bring back the attention to watch a video in $83 \%$ of the cases. Subsequently, choosing a target group- and product-specific music seems to be of high importance to keep the attention of potential customers (Strötgen, 2014). Some authors argue that it is even better to cancel the music in a commercial video ad instead of using unfitting music in regard to products and target groups (North, MacKenzie, Law, and Hargreaves, 2004).

The combination of automation and music seems to be of research interest in particular in the field of algorithmic composition (Nierhaus, 2009; Silhavy, Senkerik, Oplatkova, Silhavy, and Prokopova, 2016). For instance, mathematical models enable automatic music compositions on a random basis (Wang, Lei, Lau, and Zhang, 2012). Wang et al. (2012) recommend combining the automation with controllability. Thus, the creation process is not purely random but could be controlled by the user by choosing a genre, for example. The continuous advances of that topic are also visible by looking at the development of composing and arranging software on the market. Based on composition 
algorithms, tools such as Band-in-a-Box are able to arrange songs of different genres. The software Melodyne offers features to digitize and automate vocal tracks. This way, digitized vocals can be automatically synchronized with other sound tracks. Thus, the process of composing music can be seen as automatable.

Since the music selection for video ads is typically the job of market and media specialists (Strötgen, 2014) this article opens up the question, whether and to which extent this task can be digitized and automated derived from products and target groups. Subsequently, the present article's research question is, whether the choice of the background music of a video ad can be automated based on input data such as product type and target groups by the example of gender. In a first step, literature is reviewed to categorize video ads in line with the topic of this article. Furthermore, literature in regard to the effect of different music genres will be evaluated to have a theoretical overview about possible effects that can be reached via music. The research question will be answered by statistical testing the significant distinctness between product groups and genders based on different music genres. If that significance can be proved the music selection of video ads can be seen as automatable based on product type and gender.

\section{Literature review Classification of video ads}

A possible classification of video ads can be seen in its integration form into a website. Following that, a general differentiation can be made between in-page video ads integrated into websites and in-stream video ads that are integrated into an existing online video (Unger, Fuchs, and Michel, 2012; Mahoney, and Tang, 2016). In-page video ads are often integrated as a static banner into an existing website. By moving the mouse over the banner the video starts playing. According to Reisig and Greve (2011) in-stream video ads running in the same time dimension as the base video are often called linear video ads. Furthermore, the authors describe non-linear video ads as video ads that are uncoupled from the time of the base video. The non-linear video ads are typically overlaid and played in parallel to the original video. As an example, a non-linear video ad could be integrated within an existing video in the lower region of the screen (Reisig and Greve, 2011). This kind of overlaying technique is also used at standard TV commercial ads. Linear video ads can be sub-classified into pre-, mid- and post-roll ads (Hegner, Kusse, and Pruyn, 2015). Pre-roll ads stand for video ads that start before the base video gets started. Mid-roll ads are temporally integrated within the base video. If the video ad is integrated at the end of the base video, it is related to post-roll ads. In regard to the music context it appears obvious that non-linear videos are mainly based on visual elements. Since the video ad is running in the background of the base video the audio channel of the base video seems to be in the foreground.

From a musicological perspective, video ads can be classified in music-based videos where the video follows the music and video based ads (Bode, 2009). Video based ads are focused on visual elements and the music is derived from that. Furthermore, video-based ads can be categorized related to the visual content of the video. Walewski (2000) proposes a classification of video ads into storytelling, protagonist based or product-orientated videos. That appears to influence the music selection of the video ad since the music is accordingly derived from stories, products or protagonists. Since current evaluation is focused on analyzing background music of video ads in dependence of target groups and 
products, in particular the product-oriented video ad seems to be of relevance. Based on the topic of this paper, in-stream, linear video ads with video based music derived from products and gender are in the focus of the further analysis.

\section{Music genres and its effects}

According to Zander, the research field of music in advertisement can be categorized into the concept of involvement, the elaboration likelihood model and the concept of musical fit. The involvement concept argues that a positive stimulus based on the music can be transferred to the perception of a product. The elaboration likelihood model can be seen as a further development of the involvement concept. The concept of the music fit is focused on the fit between the audio and the video channel of a video ad (Zander 2007). Based on that, the choice of the music genre seems to be of meaning to create a desired mood (Tauchnitz, 1990). This could be explained by the high efficiency of acoustic elements in regard to cause emotions and moods (Brown 2006; Graakjær and Jantzen, 2009; Steiner, 2014). Furthermore, Strötgen (2009) recommends generating the music of a commercial ad based on a specific target group and product, for instance. However, marketers tend to select the music only when the video production is finalized. That is the reason why video and audio often doesn't fit together (Strötgen, 2009). As a result, the music channel could lead to a distraction from the product.

Often mentioned music genres are Pop, Rock, Dance, Hip Hop, Folk and Classic (Strachan, 2006; Bronner, 2007; Hofmann, 2010). In particular Rock, Dance and Classic appear to be very characteristic because these genres are based on guitars, synthesizers respectively strings. Following Beckermann and Gray (2014), these instruments can be classified as powerful, evolutionary and passionate. However, there doesn't seem to be the need to focus on one genre. For instance, Citroën used different genres such as Rock and Classic to promote a car (Strötgen, 2014). The brewery Beck GmbH \& Co. KG integrated a pop song with a characteristic voice and a slow tempo into a video ad to promote beer to men as their target group (Bronner, 2007; Strötgen, 2014). Apart from a genre-based categorization, music can be categorized by rhythm, melody, harmony, dynamics, tempo and timbre (Louven, 1998; Brown, 2006; Götz, 2011). Furthermore, Bode (2009) proposes a comprehensive categorization and divides music into voice, lyrics and music genre. Since genre is defining the rhythm, tempo, harmony, dynamics and the timbre of music, a genrebased classification of music will be used in the further process. The elements of a genre can be seen as a parameter set to generate stimuli (Bruner, 1990). For instance, a fast played music based on major chords that integrates a flowing rhythm can lead to happiness (Bruner, 1990; Vinh, 1994). Subsequently, the genre seems so be the key music segmentation criteria to differ between various moods and emotions (Esch, Roth, and Strödter, 2009). Consequently, genres could be used to achieve a desired effect on the user side. Thus, different genres seem to be suitable for different areas of use as shown in table 1. Beyond that, music can also be differed on a gender basis. For instance, Tagg (2006) found out, that women prefer slower, more dynamic music with rather acoustical instruments similar to classical music. In contrary, men seem to prefer faster music with electrical guitars that could be correlated to rock music (Tagg, 2006). 
Table 1. Effects and areas of use of music genres

\begin{tabular}{|l|l|l|l|}
\hline Music genre & Sub genre & Product image & Areas of use \\
\hline Classical & Baroque & Precision, quality & Watches, luxury goods \\
\hline & Classic & Elegance, maturity & Wine, champagne, food \\
\hline & Romance & Love, Emotions & Jewelry, fragrances \\
\hline Pop & Dance & Momentum, happiness & Drinks, luxury food \\
\hline & Rap & Protest, differentiation & Leisure and sporting goods \\
\hline & Rock & Self confidence & Beer, jeans \\
\hline & New Age & Nature, Authenticity & Food \\
\hline Jazz & & Otherness & Cosmetics, fragrances \\
\hline & Traditional folk & Down-to-earthiness & Regional products \\
\hline & Children's music & Light-heartedness & Toys, candies \\
\hline & Military music & Force, discipline & Detergents \\
\hline
\end{tabular}

PICBE | 733

\section{Research Methodology}

The current article is based on a quantitative survey, which was performed by students at the Stuttgart Media University in November/December 2016. This survey consists of a sample of $n=241$ participants within the target group of 16-30 year old persons. Users had the choice to select adequate music genres for different products. The used music genres were clustered into the five groups (i) Rock, (ii) Pop, (iii) Dance consisting of Electronic Dance Music, Hip Hop and R\&B, (iv) Relax music based on Reggae, Folk as well as Singer\& Songwriter and (v) Classic music. The participants judged the best fit of each genre in regard to a car, a hair shampoo, a fitness center, lemonade as well as a holiday trip. Based on that survey, it appears possible to test, whether a genre respectively a genre combination can differ between the five products as well as between male and female. If there are significant differences between the music selection of different products and different gender, it could be interpreted as a clear relation, which can be automated. Consequently, if no dependencies will be found, the music selection can be seen as a randomized process. Even a randomized process could be digitized. However, digitization in the context of artificial intelligence can be seen as beyond of a random generator. This can by argued within the current topic by finding the most suitable music in regard to specific objectives and not randomly. Therefore, a possible digitization respectively automation of the music selection corresponds with the significance of certain genres explaining the differences in products and gender. Related to the current evaluation the genres correspond to the independent variables and the product groups as well as the gender to the categorical variables. In a first analytical step, the genres will be tested on a univariate basis in regard to their significance towards the categorical variables. Since music often consists of different genre elements as described in the previous section, mutual interactions are to expect. Subsequently, a statistical analysis will be performed on a multivariate level in the second step. To analyze the contribution of different factors respectively independent variables to differ between categorizing variables, Backhaus, Erichson, Plinke, and Weiber (2011) recommend using a discriminant analysis. Furthermore, that method seems to be suitable to find multivariate relations since all independent variables are integrated into the calculation. From this perspective, the music selection for video ads can be seen as digitizable, if a significant multivariate model can be 
found. Furthermore, the coefficients of the discriminant function give the possibility to explain the meaning of each independent variable in regard to its contribution to the grouping capabilities of the model. Before applying the statistical tests, the dataset will be checked in regard to correlations between the independent variables and in regard to outliers (Wiesener, 2014).

\section{Results}

$67,5 \%$ of the participants of the survey is female. In regard to the age, 93\% are between 16 and 30 years old. Due to the high percentage of a small age range, the analysis in regard to the age will be neglected in the further process. However, a first difference in regard to the music choice can already be derived from the descriptive statistics. For instance, $36 \%$ of all participants chose electronic dance music as most suitable selection to promote a car. The choice in regard to the hair shampoo respectively lemonade was to $52 \%$ respectively $63 \%$ popular music. $88 \%$ sees dance music as the best choice to promote fitness centers and $52 \%$ selected relax music for promoting vacancy travels. As a summary, the descriptive results of the empirical study show already a clear tendency in regard to differences of music selection between different product groups.

Before applying the univariate and multivariate statistical analyses, the dataset was tested in regard to outliers and correlation. By analyzing the boxplots of all independent variables no extraordinaries could be observed. There were some results that could be described as out of standard. However, those extreme values did not appear on a single basis. Therefore, no data will be excluded from the dataset based on the outlier analysis. The correlation test based on a correlation matrix resulted in a maximum value of 0.3 in the relation between the independent variables Pop and Dance. Correlation values substantial below 1 can be seen as uncritical in regard to correlation problems (Backhaus et al., 2011). As a summary, no significant correlation between the independent variables could be detected. The univariate influence of each genre in regard to products and gender was proved by t-tests. As described in the previous section, the categorical variables product and gender were used as independent variable. Accordingly, the univariate test was performed for every genre as independent and the products and the gender as dependent variable, as shown in table 2 . The results based on the products as categorical variable show three genres that are highly significant in regard to differing between the various product groups. The stars beneath the value of the p-values in table 2 indicate the significance grade. Three stars correspond to highly significant values near zero. The genres Pop and Relax don't show significance in regard to the product as grouping variable. The same test based on gender as categorical variable leads to the significant genre Rock.

Table 2. Results of the univariate significance analysis

\begin{tabular}{|l|l|l|l|l|l|l|l|l|}
\hline & \multicolumn{4}{|c|}{ Categorical variable: product } & \multicolumn{3}{c|}{ Categorical variable: gender } \\
\hline Genre & $\begin{array}{l}\text { Standard } \\
\text { Error }\end{array}$ & $\mathbf{R}^{\mathbf{2}}$ & $\boldsymbol{t}$-value & $\boldsymbol{p}$-value & $\begin{array}{l}\text { Standard } \\
\text { Error }\end{array}$ & $\mathbf{R}^{\mathbf{2}}$ & $\boldsymbol{t}$-value & $\boldsymbol{p}$-value \\
\hline Rock & 0.114 & 0.013 & 3.993 & $0.000^{* * *}$ & 0.038 & 0.006 & 2.777 & $0.006^{* *}$ \\
\hline Pop & 0.085 & 0.001 & -1.226 & 0.221 & 0.028 & 0.001 & 0.778 & 0.437 \\
\hline Dance & 0.083 & 0.036 & 6.663 & $0.000^{* * *}$ & 0.028 & 0.000 & 0.609 & 0.543 \\
\hline Relax & 0.092 & 0.004 & -2.172 & $0.030^{*}$ & 0.031 & 0.000 & 0.199 & 0.842 \\
\hline Classic & 0.148 & 0.092 & -11.05 & $0.000^{* * *}$ & 0.051 & 0.000 & -0.117 & 0.907 \\
\hline
\end{tabular}


The multivariate analysis was realized via a discriminant analysis, as described in the previous sector. Analogously to the univariate analysis, one analysis is based on the product and a second one on gender as grouping variable, as shown in table 3 . The analysis regarding the products is divided in two models. Model I uses all dependent variables, whereas model II is based on only significant variables related to the univariate tests. Since the discriminant coefficients correspond to the level of contribution to the grouping function, the genres Dance, Rock and Classic in model I seem to be the independent variables with the strongest contribution. The genre Pop and Relax appear to have a negative influence on grouping the products, since their coefficients are negative. Model II neglects these two variables. The results are shown in the third column of table 3 . The fourth column shows the result of the model with gender as grouping variable. All coefficients seem to have a positive contribution to the grouping, whereas Rock and Pop explain most of the difference between the groups female and male. Therefore, no second model was calculated, even so only the genre Rock showed significance in the univariate testing. The F-Value and the model significance is shown in the last row of table 3 . All models show high significance. Therefore, the music selection of video ads seems to be digitizable and automatable.

Table 3. Results of the discriminant analysis

\begin{tabular}{|l|l|l|l|}
\hline & \multicolumn{2}{|c|}{ Categorical variable: product } & Categorical variable: gender \\
\hline Genre & $\begin{array}{l}\text { Discriminant } \\
\text { coefficients }\end{array}$ & $\begin{array}{l}\text { Discriminant } \\
\text { coefficients }\end{array}$ & $\begin{array}{l}\text { Discriminant } \\
\text { coefficients }\end{array}$ \\
\hline Rock & 0.9755925 & 1.7055058 & 2.7732696 \\
\hline Pop & -0.9107146 & & 1.2563767 \\
\hline Dance & 1.1727010 & 2.1712098 & 1.0036424 \\
\hline Relax & -1.8234880 & & 0.9528127 \\
\hline Classic & 0.3743120 & 0.8307923 & 0.6842395 \\
\hline \multicolumn{4}{|l}{} \\
\hline $\begin{array}{l}\text { F-value/ } \\
\text { Significance }\end{array}$ & $250.889612 / 0.000$ & $141.496257 / 0.000$ & $12.58924 / 0.000$ \\
\hline
\end{tabular}

Source: Authors' own research.

\section{Conclusion}

This paper can be seen as an explorative study to test a gender- and product-specific music selection for video ads. The base theoretical thought is grounded on the idea that machines could easily learn repeatable processes. Repeatable in the context of music selection can be interpreted as a significant correlation between music style and product respectively gender. In regard to products it was shown that the three genres Rock, Dance and Classic contribute significantly to differ between various product groups. This could be explained by the general characteristics of these genres, which integrate guitars, a driving rhythm and classical instruments. Those musical elements have a strong expressive, characteristic effect as described in the literature review section. On a gender-based view only one significant genre could be identified. However, the remaining genres with no significant influence on the different products and the gender could also be seen as important information since music genres often get combined. For instance, if Rock is the key genre in regard to a product and target group, it seems reasonable to integrate also other musical elements even though they show lower contributions. As a result, this could end up in a slow, relaxing Rock music with classical elements and thus, combining the music genres based on their 
degree of contribution. Consequently, if the music selection for a product group such as a shampoo or a fitness center seems to be gender-independent, marketers don't have to differentiate in this context. From a multivariate perspective all models shown in the previous section are highly significant. That demonstrates, that there are multivariate effects. Therefore, a genre combination related to the contribution level of the single genres seems to be recommendable. As a summary, there are observable, significant differences between the genre combination of different products and gender. Thus, a digitization and subsequently, an automation of the music selection based on products and gender seems to be possible.

The empirical basis of this evaluation is restricted in regard to the target group since the age of most of the participants is between 16 and 30 years. Therefore, the results of this study have no validity for persons of other ages. Furthermore, the dataset consists of only five product groups and one product variant per group. In regard to cars, for instance, there could be a difference in music depending on the brand and the price of the car. Subsequently, the result of this study can be classified as a first, rough overview in regard to automation possibilities. Additionally, this paper can be seen as a preliminary step towards the research in regard to the digitization of the music selection of video ads. If music genres can be used to separate products and partly genders, also a selection of music styles based on products and target group appears to be realizable via artificial intelligence. Subsequently, a next research step towards the digitization could be a more comprehensive market survey in regard to a wider range of products and target groups. A generalized model could be achieved with an artificial neural network, for instance. In this context a redefinition of the product characteristics seems to be reasonable to get a metric scale for the independent variables. Once digitized, an adequate interface to tools with the capability of composing and arranging music would extend the automation starting from the music selection to the final music production. As a result, marketers would just enter details of their product and their target group as input for neural networks and receive final produced background music. However, even in that scenario, the final decision is still on the human side.

\section{References}

Backhaus, K., Erichson, B., Plinke, W., \& Weiber, R. (2011). Multivariate Analysemethoden: Eine anwendungsorientierte Einführung. Heidelberg, Germany: Springer.

Beckerman, J. \& Gray, T. (2014). The Sonic Boom: How Sound Transforms the Way We Think, Feel, and Buy. Indianapolis, United States: Houghton Mifflin Harcourt.

Bertoni, A., \& Geiling, R. (2003). Funktion der Musik in der Werbung. In R. Moser \& A. Scheuermann (Eds.), Handbuch der Musikwirtschaft, pp. 415-428. München, Germany: Musikmarkt.

Bode, M. (2009). Making sense of music in advertising research. In N. Graakjær \& C. Jantzen (Eds.), Music in Advertising: Commercial Sounds in Media Communication and Other Settings, pp. 75-98. Aalborg, The Netherlands: Aalborg University Press.

Bronner, K. (2007). Schöner die Marken nie klingen... jingle all the way? Grundlagen des Audio-Branding. In K. Bronner (Ed.), Audio-Branding: Entwicklung, Anwendung, Wirkung akustischer Identitäten in Werbung, Medien und Gesellschaft, pp. 82-96. Baden-Baden, Germany: Nomos. 
Bruner, G.C. (1990). Music, Mood and Marketing. Journal of Marketing, 54(4), 94-104.

Brown, S. (2006). Introduction: "how does music work?" toward a pragmatics of musical communication. In S. Brown \& U. Volgsten (Eds.), Music and Manipulation: On the Social Uses and Social Control of Music, pp. 1-23. New York, United States: Berghahn Books.

Esch, F.R., Roth S., \& Strödter, K. (2009). Wirkungen akustischer Reize in der Markenkommunikation. In M. Bruhn, F.R. Esch, \& T. Langner (Eds.), Handbuch Kommunikation: Grundlagen - Innovative Ansätze - Praktische Umsetzungen, pp. 755774. Wiesbaden, Germany: Springer.

Graakjær, N. \& Jantzen, C. (2009). Music for shopping. In N. Graakjær \& C. Jantzen (Eds.), Music in Advertising: Commercial Sounds in Media Communication and Other Settings, pp. 237-258. Aalborg, The Netherlands: Aalborg University Press.

Götz, S. (2011). Corporate Sound: Identifikation wahrgenommener akustischer Dimensionen in der Markenführung. Arbeitspapier zur Schriftenreihe Schwerpunkt Marketing. Norderstedt, Germany: Books on Demand.

Hegner, S.M., Kusse, D.C., \& Pruyn, A.T.H (2015). Watch it! The Influence of Forced Pre-Roll Video Ads on Consumer Perception. In P. Verlegh, H. Voorveld, \& M. Eisend (Eds.), Advances in Advertising Research (Vol. VI): The Digital, the Classic, the Subtle, and the Alternative, pp. 63-73. Wiesbaden, Germany: Springer.

Hofmann, B. (2010). Volles Ohr! Musik in der Hörfunkwerbung. In A. Bode \& C. Mueller (Eds.), Mit Medienmusik erfolgreich in der Kreativwirtschaft: ein praxisorientierter Leitfaden für die professionelle Musiknutzung in der Kreativwirtschaft, pp. 148-171. München, Germany: Musikmarkt.

Louven, C. (1998). Die Konstruktion von Musik: theoretische und experimentelle Studien zu den Prinzipien der musikalischen Kognition. Systemische Musikwissenschaft. Frankfurt, Germany: Peter Lang.

Mahoney, L. M., \& Tang, T. (2016). Strategic Social Media: From Marketing to Social Change. Chichester, United Kingdom: Wiley.

Nierhaus, G. (2009). Algorithmic Composition: Paradigms of Automated Music Generation. Mathematics and Statistics. Wien, Austria: Springer.

North, A. C., MacKenzie, L. C., Law, R. M., \& Hargreaves, D. J. (2004). The effects of musical and voice "fit" on responses to advertisements. Journal of Applied Social Psychology, 34 (8), pp. 1675-1708.

Reisig, D., Runge, F., \& Greve, G. (2011). Targeting with invideo advertising. In C. Bauer, G. Greve, \& C. Hopf (Eds.), Online Targeting und Controlling: Grundlagen Anwendungsfelder - Praxisbeispiele, pp. 243 - 260. Wiesbaden, Germany: Gabler.

Schramm, H. (2007). Wirkungen von Musik. In B. Schneider (Ed.), Musikwirtschaft und Medien: Märkte - Unternehmen - Strategien, pp. 135-153. Frankfurt, Germany: Fischer.

Silhavy, R., Senkerik, R., Oplatkova, Z. K., Silhavy, P., \& Prokopova, Z. (2016). Artificial Intelligence Perspectives in Intelligent Systems: Proceedings of the 5th Computer Science On-line Conference 2016 (CSOC2016). In N. Shakhovska (Ed.), Advances in Intelligent Systems and Computing. Cham, Switzerland: Springer.

Steiner, P. (2014). Sound Branding: Grundlagen akustischer Markenführung. Wiesbaden, Germany: Springer. 
Strötgen, S. (2009). Die zarteste Versuchung, wenn's ums Geld geht. Musik in der Fernsehwerbung. In P. Moormann (Ed.), Musik im Fernsehen: Sendeformen und Gestaltungsprinzipien, pp 105-134. Wiesbaden, Germany: VS.

Strötgen, S. (2014). Markenmusik. Thurnauer Schriften zum Musiktheater, Würzburg, Germany: Königshausen \& Neumann.

Strachan, M. (1994). Music Video and Genre. In H.M. Macbeth (Ed.), Food Preferences and Taste: Continuity and Change, pp. 187-204. United States: Berghahn Books.

Tagg, P. (2006). Music, moving images, semiotics, and the democratic right to know. In: S. Brown \& U. Volgsten (Eds.), Music and Manipulation: On the Social Uses and Social Control of Music, pp. 163-186. New York, United States: Berghahn Books.

Tauchnitz, J. (1990). Werbung mit Musik: Theoretische Grundlagen und experimentelle Studien zur Wirkung von Hintergrundmusik in der Rundfunk- und Fernsehwerbung. Konsum und Verhalten. Heidelberg, Germany: Physica.

Unger, F., Fuchs, W., \& Michel, B. (2012). Mediaplanung: Methodische Grundlagen und praktische Anwendungen. Berlin, Germany: Springer.

Vinh, A. L. (1994). Die Wirkungen von Musik in der Fernsehwerbung. St. Gallen, Switzerland: no publ.

Walewski, M. (2000). Musik in der Fernsehwerbung: eine empirische Untersuchung des durch TV-Werbemusik ausgelösten Wirkungsprozesses. Münster, Germany: Universität Münster.

Wang, F. L., Lei, J., Lau, R. W. H., \& Zhang, J. (2012). Multimedia and Signal Processing: Second International Conference, CMSP 2012, Shanghai, China, December 7-9. Berlin, Germany: Springer.

Wiesener, 0. (2014). Mit mehrstufigem Wissenserwerb zu mehr Innovationserfolg. Wiesbaden, Germany: Springer.

Zander, M. \& Kapp M. (2007). Verwendung und Wirkung von Musik in der Werbung: Schwarze zahlen durch "blaue Noten"? In H. Schramm (Ed.), Musik und Medien, pp. 92-104. München, Germany: UKV. 